\title{
Effect of Piezoelectric polarization on Open Circuit Voltage of GaN/InGaN MQW Solar Cell
}

\author{
Manoj Thosar ${ }^{1}$, R. K. Khanna ${ }^{2}$, Saurabh Khandelwal ${ }^{3}$, Shubham Faujdar ${ }^{4}$ \\ ${ }^{1}$ Department of Physics, Vivekananda Institute of Technology - East, VIT-Campus, Jaipur, India, \\ ${ }^{2}$. Department of Physics, Vivekananda Global University, VIT-Campus, Jaipur, India, \\ ${ }^{3}$. Department of Mechanical Engg., Vivekananda Institute of Technology - East, VIT-Campus, Jaipur, India \\ ${ }^{4}$. Department of Mechanical Engg., Vivekananda Institute of Technology - East, VIT-Campus, Jaipur, India
}

\begin{abstract}
The piezoelectric polarization effect is dominant at the every GaN/InGaN interface in the MQW structure. In this paper we show that, how this piezoelectric polarization effect is useful in improving the open circuit voltage of GaN/InGaN MQW solar cell. For this purpose we have design a mathematical model of GaN/InGaN MQW solar cell and calculate the values of open circuit voltage with and without piezoelectric polarization effect. For simplicity of the model we are neglecting the current clouding effect, composition fluctuation and electro migration effect present in the device. Here we also assuming that, all the layers of GaN and InGaN material are terminated by Ga-face. Results indicate that the open circuit voltage of $M Q W$ solar cell improves by $\sim 6.28 \%$ (at indium fraction in quantum well is 0.2 and quantum well thickness is $1 \mathrm{~nm}$ ) and by $\sim 16.77 \%$ (at indium fraction in quantum well is 0.2 and quantum well thickness is $3 \mathrm{~nm}$ ) by using piezoelectric polarization effect.
\end{abstract}

Keywords: Dislocation density, Ga-face GaN and InGaN layer, Gallium nitride (GaN), Indium gallium nitride (InGaN), Multi quantum well (MQW), piezoelectric polarization

\section{Introduction}

The III-nitrides offer substantial potential to develop ultra high efficiency solar cells due to their direct band gap ranging from $0.7 \mathrm{eV}(\mathrm{InN})$ to $6.2 \mathrm{eV}$ ( $\mathrm{AlN}$ ) [1]. The InGaN material system offers a wide range of direct band gaps that spans the bulk of the solar spectrum. Additional advantages of this material system includes low effective mass of electron and hole, high mobility, high peak and saturation velocity, high absorption coefficient and radiation tolerance [2]. These features enable InGaN for third generation photovoltaics. A unique feature of the III-nitride is strong polarization and piezoelectric effect [3, 4]. It has been theoretically calculated and confirmed experimentally [5] that the III-nitrides are highly polar molecules due to the non-centrosymmetry of charge in the wurtzite structure and large ionicity of the covalent bonds. This polarization can be used constructively in MQW solar cell design.

Multi quantum well structure is used for improving carrier confinement in active region for light emitting devices such as LEDs and laser diodes. The purpose of increasing carrier confinement is to increase the internal quantum efficiency of light emitters by increasing radiative recombination rate. In the case of solar cell the overall efficiency of the solar cell decreases due to radiative and non-radiative recombination, because recombination reduces the number of charge carriers reaches at the output terminals. Other than this the trapping centers (recombination centers) are present at the GaN/InGaN interface in the MQW structure which traps the photo generated charge carriers. Thus the overall efficiency of the solar cell decreases due to MQW structure.

The GaN/InGaN MQW structure provide its own advantages. The biggest advantage is that it helps to absorb larger solar spectrum by arranging the absorption edges of the quantum wells in descending order (from $3.42 \mathrm{eV}$ to $0.7 \mathrm{eV}$ ) [1]. The piezoelectric polarization is dominant at the interface of $\mathrm{GaN} / \mathrm{InGaN}$ layers in the MQW structure due to lattice mismatch and different thermal expansion coefficients. This piezoelectric polarization develops a potential across the each $\mathrm{GaN} / \mathrm{InGaN}$ interface layer. If the direction of this piezoelectric potential is identical with the built-in potential of the solar cell than the open circuit voltage across the solar cell is the sum of both the built-in potential and the total piezoelectric potential develop across the all interface layers in the MQW. Therefore the overall external quantum efficiency of the solar cell increases due to piezoelectric polarization. In this paper we present a theoretical study for calculating the effect of piezoelectric polarization on the open circuit voltage of the GaN/InGaN MQW solar cell.

\section{Model}

As mentioned earlier the MQW structure provides the facility to absorb the larger solar spectrum. This can be done by increasing the indium composition in the InGaN layer or by increasing the thickness of the InGaN layer in MQW structure from front end to back end. Both these methods have it own advantages and disadvantages. If we use the first method to absorb larger solar spectrum, then the trapping centers and 
dislocation density at the $\mathrm{GaN} / \mathrm{InGaN}$ interface increases with increasing indium composition which increases the absorption of the photo-generated charge carriers at the interface and decreases the shunt resistance of the MQW solar cell due to dislocation density. The advantage of this method is that, it helps to maintain the gradual increase in piezoelectric potential across each $\mathrm{GaN} / \mathrm{InGaN}$ interface from front end to back end in MQW structure. If we use second method, the carrier confinement of photo-generated charge carriers decreases with increasing well thickness which increases the heat in the solar cell due to phonon generation. This method makes the device thicker in depletion region which decreases the electric field across the depletion layer therefore reduces the drift velocity of photo-generated charge carriers. By using this method it is very difficult to utilize the effect of piezoelectric polarization for increasing open circuit voltage because piezoelectric polarization decreases very sharply with increasing well thickness. There are two advantages of this method:

1. Effect of composition fluctuation is minimized by increasing heat and

2. It controls the number of trapping centers and dislocation density in the MQW structure.

All the parameters of MQW solar cell such as trapping centers, dislocation density, shunt resistance, effect of composition fluctuation on radiative recombination rate, absorption range of solar spectrum, and series resistance is depend on the indium composition and well thickness. Therefore it is very difficult to optimize the value of indium composition and well thickness for GaN/InGaN MQW solar cell. Our aim is to utilize the piezoelectric potential developed across the GaN/InGaN interface in the MQW structure for increasing open circuit voltage of the solar cell. For the simplicity of theoretical analysis we are taking constant indium composition in each well region and identical well thickness $\left(<\ell_{\mathrm{c}}\right)$ which provides the identical piezoelectric potential across each GaN/InGaN interface in the MQW structure. The GaN/InGaN MQW solar cell with orientation of piezoelectric potential and built-in potential is shown in fig. 1.

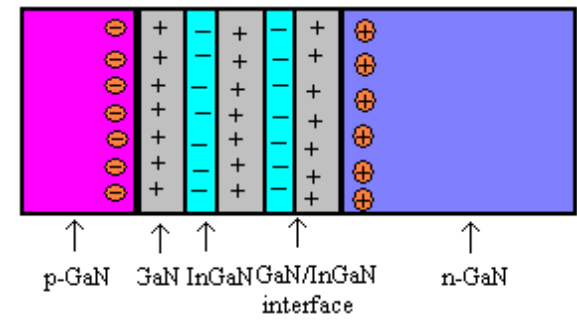

Fig. 1 Piezoelectric field in GaN/InGaN MQW solar cell structure

The spontaneous polarization $\left(\mathrm{P}_{\mathrm{sp}}\right)$ of $\mathrm{Ga}$-face $\mathrm{InGaN}$ layer in terms of Indium composition $(\mathrm{x})$ is given by equ. 1. [6]

$\mathrm{P}_{\mathrm{sp}}=-0.003 \times \mathrm{x}-0.029$

Spontaneous polarization is the inherent property of the InGaN layer and produced due to non-centrosymmetry property of the wurtzite structure. The piezoelectric polarization in InGaN layer is developed due to lattice mismatch and different thermal expansion coefficient between GaN and InGaN layers. These piezoelectric polarization charges are distributed identically in the entire thickness of the InGaN layer for the well thickness less than $3 \mathrm{~nm}$. The value of piezoelectric polarization $\left(\mathrm{P}_{\mathrm{pz}}\right)$ in terms of Indium composition $(\mathrm{x})$ is given by equ. 2. [7]

$\mathrm{P}_{\mathrm{pz}}=0.176 \times \mathrm{x}$

The net polarization is the sum of both spontaneous polarization and piezoelectric polarization in InGaN layer. $\mathrm{P}=\mathrm{P}_{\mathrm{sp}}+\mathrm{P}_{\mathrm{pz}}$

The net polarization electric field across each quantum well is given by equ. 4. [8]

$\mathrm{E}_{\mathrm{P}}=-(\mathrm{P} / \varepsilon)$

Where $\varepsilon$ is the permittivity of the InGaN layer and calculated by $\varepsilon=\varepsilon_{0} \times \varepsilon_{\mathrm{r}}$ where $\varepsilon_{0}$ is the vacuum permittivity and $\varepsilon_{\mathrm{r}}$ is the relative permittivity and is calculated by $\varepsilon_{\mathrm{r}}=10.4+(3.9 \times \mathrm{x})$ [9] where $\mathrm{x}$ is the indium composition of InGaN layer.

The open circuit voltage $\left(\mathrm{V}_{\mathrm{OC} 1}\right)$ of a simple homo-junction $\mathrm{GaN}$ solar cell is the maximum voltage available across the solar cell for zero current and is given by equ. 5. [10]

$\mathrm{V}_{\mathrm{OC} 1}=\frac{K T}{q} \times \ln \left[\left(\mathrm{I}_{\mathrm{sc}} / \mathrm{I}_{0}\right)+1\right]$

Where $\mathrm{K}$ is the Boltzmann constant, $\mathrm{T}$ is the operating temperature of the solar cell, q electronic charge, $\mathrm{I}_{\mathrm{sc}}$ is the photo-generated current and $\mathrm{I}_{0}$ is the reverse saturation current in the solar cell. The reverse saturation current in simple homo-junction $\mathrm{GaN}$ solar cell is given by [10]

$\mathrm{I}_{0}=\mathrm{qA} \times\left[\left(\mathrm{D}_{\mathrm{n}} \times \mathrm{n}_{\mathrm{i}}{ }^{\mathrm{P}-\mathrm{GaN}}\right) /\left(\mathrm{L}_{\mathrm{n}} \times \mathrm{N}_{\mathrm{A}}{ }^{\mathrm{P}-\mathrm{GaN}}\right)+\left(\mathrm{D}_{\mathrm{P}} \times \mathrm{n}_{\mathrm{i}}^{\mathrm{n}-\mathrm{GaN}}\right) /\left(\mathrm{L}_{\mathrm{p}} \times \mathrm{N}_{\mathrm{D}}{ }^{\mathrm{n}-\mathrm{GaN}}\right)\right]$

Where $A$ is the cross section area of the solar cell, $D_{n}$ and $D_{P}$ is the diffusion coefficients for electrons in $p-G a N$ and for holes in $\mathrm{n}-\mathrm{GaN}$ and calculated by $\mathrm{D}_{\mathrm{n}}=\frac{K T}{q} \mu_{\mathrm{n}}$ and $\mathrm{D}_{\mathrm{P}}=\frac{K T}{q} \mu_{\mathrm{p}}$ Where 
$\mu_{\mathrm{n}}$ and $\mu_{\mathrm{p}}$ is the mobility of electron and hole. The $\mathrm{L}_{\mathrm{n}}$ and $\mathrm{L}_{\mathrm{p}}$ are the minority carrier electron and hole diffusion lengths and calculated by $L_{n}=\left[D_{n} \tau_{n}\right]^{1 / 2}$ and $L_{P}=\left[D_{P} \tau_{P}\right]^{1 / 2}$ Where $\tau_{n}$ and $\tau_{P}$ is the average recombination time for electrons and holes and calculated by $\tau_{\mathrm{n}}=1 / \mathrm{B} \mathrm{N} \mathrm{A}^{\mathrm{P}-\mathrm{GaN}}$ and $\tau_{\mathrm{P}}=1 / \mathrm{B} \mathrm{N}_{\mathrm{D}}{ }^{\mathrm{n}-\mathrm{GaN}}$ Where $\mathrm{B}$ is the bimolecular radiative rate coefficient of $\mathrm{GaN}, \mathrm{n}_{\mathrm{i}}{ }^{\mathrm{P}-\mathrm{GaN}}$ is the intrinsic concentration in $\mathrm{p}-\mathrm{GaN}, \mathrm{n}_{\mathrm{i}}^{\mathrm{n}-\mathrm{GaN}}$ is the intrinsic concentration in $\mathrm{n}-\mathrm{GaN}, \mathrm{N}_{\mathrm{A}}{ }^{\mathrm{P}-\mathrm{GaN}}$ is the external doping in $\mathrm{p}-\mathrm{GaN}$ and $\mathrm{N}_{\mathrm{D}}{ }^{\mathrm{n}-\mathrm{GaN}}$ is the external doping in $\mathrm{n}-\mathrm{GaN}$.

The built-in voltage $\mathrm{V}_{\mathrm{bi}}$ for a simple homo-junction $\mathrm{GaN}$ p-n junction diode is given by equ. 7. [10]

$\mathrm{V}_{\mathrm{bi}}=\frac{K T}{q} \times \ln \left[\left(\mathrm{N}_{\mathrm{A}}^{\mathrm{P}-\mathrm{GaN}} \mathrm{N}_{\mathrm{D}}^{\mathrm{n}-\mathrm{GaN}}\right) /\left(\mathrm{n}_{\mathrm{i}}^{\mathrm{P}-\mathrm{GaN}} \mathrm{n}_{\mathrm{i}}^{\mathrm{n}-\mathrm{GaN}}\right)\right]$

This is the maximum value of the open circuit voltage in the ideal case of the GaN solar cell. The ratio of the practical value of open circuit voltage $V_{o c 1}$ and ideal value of open circuit voltage (built-in voltage) $V_{b i}$ of a simple $\mathrm{p}-\mathrm{GaN} / \mathrm{n}-\mathrm{InGaN}$ heterostructure solar cell gives the loss factor $(\mathrm{F})$.

$\mathrm{F}=\mathrm{V}_{\mathrm{OC} 1} / \mathrm{V}_{\mathrm{bi}}$

This loss factor (F) introduces in this study because different phenomena's of carrier losses are occur in the entire structure of the solar cell which reduces the output voltage of the solar cell.

When a MQW is inserted into the depletion region of homo-junction GaN solar cell an additional voltage is developed in the depletion region due to piezoelectric field at every GaN/InGaN interface. Then the total polarization voltage developed in MQW is the total of all the voltages develop in each individual interface and calculated by [8].

$\mathrm{V}_{\mathrm{P}}=-\mathrm{E}_{\mathrm{P}} * \mathrm{~d}_{\mathrm{w}}$

Where $d_{w}$ is the total thickness of quantum wells and calculated by $d_{w}=d_{1}+d_{2}+d_{3}+d_{4}$ where $d_{1}, d_{2}, d_{3}$ and $d_{4}$ are the individual thickness of each quantum well. The $E_{P}$ is the piezoelectric field in single quantum well. This polarization voltage $\left(\mathrm{V}_{\mathrm{P}}\right)$ develops in the same region where the built-in voltage $\left(\mathrm{V}_{\mathrm{bi}}\right)$ is developed. Thus polarization voltage will suffer from the same carrier losses which work for built-in voltage. Then the increase in open circuit voltage due to net polarization electric field is calculated by multiplying polarization voltage $\left(V_{P}\right)$ with factor $(\mathrm{F})$.

$\mathrm{V}_{\mathrm{OC} 2}=\mathrm{F} * \mathrm{~V}_{\mathrm{P}}$

Thus the total open circuit voltage $\left(\mathrm{V}_{\mathrm{OC}}\right)$ is sum of both the parts of open circuit voltage developed due to builtin voltage and polarization induced voltage.

$\mathrm{V}_{\mathrm{OC}}=\mathrm{V}_{\mathrm{OC} 1}+\mathrm{V}_{\mathrm{OC} 2}$

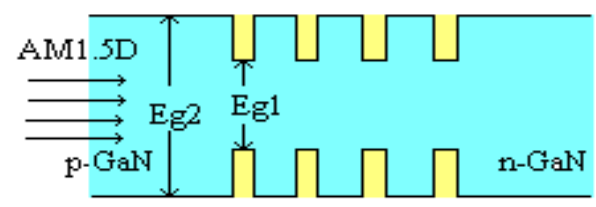

Fig. 2 Energy band diagram of GaN/InGaN MQW solar cell

Fig. 2 shows the energy band diagram of GaN/InGaN MQW solar cell and according to that the photons with energy greater than $E_{\mathrm{g} 2}$ is absorbed by the top p-type GaN layer and photons with energies between $E_{\mathrm{g} 2}$ and $E_{\mathrm{g} 1}$ are absorbed by the smaller band gap InGaN well layer. Thus the resultant short circuit current of this MQW solar cell is limited by the smaller band gap region.

$\mathrm{I}_{\mathrm{SC}}=\mathrm{q} \times \mathrm{A} \times[1-\alpha(\mathrm{x})] \times[1-\mathrm{R}] \times \int_{\lambda E g 2}^{\lambda E^{\prime} 1} N(\lambda)\left(\mathrm{dn}_{\mathrm{ph}} / \mathrm{d} \lambda\right) \mathrm{d} \lambda$

Where $\mathrm{A}$ is the front cross section area of solar cell, $\alpha(\mathrm{x})$ is the absorption of optical power with respect to distance. Studies indicate that in $\mathrm{GaN} \sim 99 \%$ optical power is absorbed at $500 \mathrm{~nm}$ distance [11], $\mathrm{R}$ is the reflectance at air-GaN interface $(\sim 18 \%)[12,13], N(\lambda)$ is the Collection efficiency represents how many electron-hole pairs generate from the absorbed photons, $\mathrm{dn}_{\mathrm{ph}} / \mathrm{d} \lambda$ is the number of incident photons per $\mathrm{cm}^{2}$ per second at particular wavelength of solar spectrum and calculated using $2 \pi v \mathrm{c}^{2} /[\exp (\mathrm{hv} / \mathrm{KT})-1], \lambda E_{g} 2$ is the Wavelength corresponding to band gap of $\mathrm{GaN}$ layer and $\lambda E g 1$ is the Wavelength corresponding to band gap of InGaN well layer.

\section{Calculation and Results}

We use the following parameters for calculating the open circuit voltage and short circuit current of the MQW solar cell listed in table 1. The calculated value of short circuit current in MQW solar cell is $1.8 \mathrm{~mA} / \mathrm{cm}^{2}$ for AM1.5D spectrum and the value of open circuit voltage without considering piezoelectric polarization field at the $\mathrm{GaN} / \mathrm{InGaN}$ interface is $2.32 \mathrm{~V}$. For $1 \mathrm{~nm}$ quantum well thickness, the open circuit voltage with considering piezoelectric polarization field at the $\mathrm{GaN} / \mathrm{InGaN}$ interface is $2.48 \mathrm{~V}$ and for $3 \mathrm{~nm}$ quantum well thickness, the open circuit voltage is $2.79 \mathrm{~V}$. 


\begin{tabular}{|c|c|c|}
\hline S. No. & Parameters & Values \\
\hline 1 & Indium composition (x) & 0.2 \\
\hline 2 & External doping in p-GaN & $5 \times 0^{17} \mathrm{~cm}^{-3}$ \\
\hline 3 & External doping in n-GaN & $5 \times 10^{18} \mathrm{~cm}^{-3}$ \\
\hline 4 & Intrinsic concentration in GaN[14] & $2.35 \times 10^{-10} \mathrm{~cm}^{-3}$ \\
\hline 5 & Reflectance at air-GaN interface[12, 13] & 0.18 \\
\hline 6 & Collection efficiency & 0.7 \\
\hline 7 & Temperature equivalent voltage & $0.026 \mathrm{~V}(300 \mathrm{~K})$ \\
\hline 8 & Mobility of electron [14] & $440 \mathrm{~cm}^{2} / \mathrm{V} . \mathrm{sec}$ \\
\hline 9 & Mobility of hole [14] & $10 \mathrm{~cm}^{2} / \mathrm{V} . \mathrm{sec}$ \\
\hline 10 & Cross section area of solar cell & $1 \times 1 \mathrm{~cm}^{2}$ \\
\hline 11 & Direct recombination capture coefficient & $2.2 \times 10^{-10} \mathrm{~cm}^{3} / \mathrm{sec}$. \\
\hline 12 & Solar spectrum & $\mathrm{AM} 1.5 \mathrm{D}$ \\
\hline 13 & Number of quantum wells & 4 \\
\hline
\end{tabular}

Table1. Solar cell parameters with their values

\section{Conclusions}

The open circuit voltage of MQW solar cell increases with increasing indium fraction in InGaN quantum well region due to increase in piezoelectric field at the GaN/InGaN interface. But dislocation density and absorption centers also increases with increasing indium fraction in InGaN quantum well region, which reduces the efficiency of the MQW solar cell, Therefore this tradeoff between piezoelectric polarization field and dislocation density imposes the limit on the performance of GaN/InGaN MQW solar cell. Results indicate that the open circuit voltage of MQW solar cell improves by $\sim 6.28 \%$ (at indium fraction 0.2 and quantum well thickness is $1 \mathrm{~nm}$ ) and $\sim 16.77 \%$ (at indium fraction 0.2 and quantum well thickness is $3 \mathrm{~nm}$ ) by using piezoelectric polarization effect.

\section{Acknowledgement}

I express my sincere gratitude to Dr. M. Raisighani (Vice-President, VIT-Campus), Er. Gaurav Bagaria (Director, VIT-Campus), Dr. Baldev Singh (Principal, VIT-East), Ms. Reshma Choudhari (Registrar, VIT-East) and Dr. Menka Bhasin (HOD, I-Yr, VIT-East) for their encouragement and kind approval. I also express my sincere gratitude to my father Mr. M. W. Thosar as they have always been an inspiration for me to learn higher and better. Without his kind patronage, the work would not have been completed successfully.

\section{References}

[1] O. Jani, C. Honsberg, Y. Huang, J. O. Song, I. Ferguson, G. Namkoong, E. Trybus, A. Doolittle, S. Kurtz, "Design, Growth, Fabrication and Characterization of High-Band Gap InGaN/GaN Solar Cells", Proc. of the IEEE $4^{\text {th }}$ World Conference on Photovoltaic Energy Conversion, Waikoloa, Hawaii, May 7-12, 2006.

[2] Y. Nanishi, Y. Saito and T. Yamaguchi, "R-F Molecular Beam Epitaxy Growth and Properties of InN and Related Alloys", Jpn. J. Appl. Phys., 42 (2003), p. 2549.

[3] F. Bernardini, and V. Fiorentini, "Nonlinear Macroscopic Polarization in III-V Nitride Alloys", Phys. Rev. B, 64 (2001), p. $085207 / 1$.

[4] V. Fiorentini F. Bernardini, "Spontaneous versus Piezoelectric Polarization in III-V Nitrides: Conceptual Aspects and Practical Consequences”, Phys. Stat. Sol. B, 216 (1999), p. 391.

[5] O. Ambacher, J. Smart, J. R. Shealy, N. G. Weimann, K. Chu, M. Murphy,W. J. Schaff, L. F. Eastman, R. Dimitrov, L. Wittmer, M. Stutzmann, W.Rieger, and J. Hilsnbeck, "Two-dimensional electron gases induced by spontaneous and piezoelectric polarization charges in N- and Ga-face AlGaN/GaN heterostructures,” J. Appl. Phys. 85 (1999), p. 3222.

[6] Rudiger Quay: Gallium Nitride Electronics, Springer Series In Materials Science 96(2008), Page 30.

[7] H. Morkoc: Nitride Semi-conductor and Devices, Springer Series In Materials Science 32(1999), Page 73.

[8] Volume 16, III-V Nitride Semiconductors: Applications \& Devices, Edited by E.T. Yu and M.O. Manasreh, Taylar \& Francis group(2003), Page 422.

[9] Th. Gessmann,Y.L. Li, E. L.Waldron, J. W. Graff, E. F. Schubert, and J.K. Sheu, "Novel Type of Ohmic Contacts to P-Doped GaN Using Polarization Fields in Thin InGaN Capping Layers" Journal of ELECTRONIC MATERIALS, Vol. 31, No. 5, (2002)

[10] S. M. Sze, “Physics of Semiconductor Devices,” John Wiley and Sons, New York,(1969).

[11] Omkar Jani, Ian Ferguson, Christiana Honsberg, Sarah Kurtz "Design and characterization of GaN/InGaN solar cells" Applied Physics Lett., vol. 91, p. 132117 (2007).

[12] E. A. Berkman, N. A. El-Masry, A. Emara, and S.M. Bedair, "High efficiency GaN/InGaN multi-junction solar cell" Appl. Phys. Lett., vol. 92, p. 101118, (2008).

[13] M. J. Bergmann, U. Ozgur, J. Casey, H. O. Everitt, and J. F. Muth, "Spontaneous and piezoelectric polarization in III-nitride materials" Appl.Phys. Lett., vol. 75, p. 67 (1999).

[14] Omkar Jani, Christiana Honsberg, Ali Asghar, David Nicol, Ian Ferguson, Alan Dwliffle, Sarah Kurtz Characterization and analysis of InGaN photovoltaic devices, Photovoltaic 31st IEEE Specialists Conference, Lake Buena, Vista, FL Jan. 3-5 (2005) 